\title{
THE DISTRIBUTION AND METABOLISM OF CARBON-LABELED UREA IN PREGNANT PRIMATES *
}

\author{
By DONALD L. HUTCHINSON, WILLIAM T. KELLY, EMANUEL A. FRIEDMAN \\ AND ALBERT A. PLENTL $\dagger$ \\ (From the Department of Obstetrics and Gynecology, Columbia University College of Physi- \\ cians and Surgeons, New York, N. Y., and the Department of Obstetrics \\ and Gynecology, Uniz'ersity of California School of Medicine, \\ Los Angeles, Calif.)
}

(Submitted for publication March 9, 1961; accepted May 11, 1962)

The concentrations of urea in maternal and in fetal blood are nearly the same for most animals and humans in which comparisons have been made (1). A rise in the maternal urea concentration produced artificially or due to pathologic changes leads to the rapid equilibration of this substance in both circulations (2). The placenta does not seem to offer an effective barrier to the passage of urea, and it has, therefore, been assumed that this metabolite diffuses freely in either direction (3).

The amniotic fluid also contains urea $(4,5)$. Its concentration is usually higher than that of maternal and of fetal blood and increases with the age of gestation (6). This and other indirect evidence gave rise to the belief that the amniotic fluid is a product of the fetal kidneys that is discharged into the amniotic cavity, its quantity regulated by fetal deglutition. The excreted urea can thus find its way back into the fetal circulation. Free diffusion into the maternal circulation across the placenta is thought to be the final pathway for its removal.

The cardinal feature in these exchanges relates to the postulated existence of a rapid and continuous transfer of urea from fetus to mother for which no definitive evidence exists at the present time. It is the purpose of this report to examine these concepts by means of tracer techniques, to present evidence for the existence of such exchanges, and to estimate within broad limits the amount of urea transferred per unit of time. The inaccessibility of the human fetus before delivery and the use of $\mathrm{C}^{14}$-labeled compounds made it

* This investigation was supported by a grant-in-aid from the National Institutes of Health, Bethesda, Md.

† Investigator of the Health Research Council of the City of New York under Contract I-225. necessary to perform these experiments on pregnant primates.

\section{METHODS}

Radiochemicals. All radiochemicals were obtained from commercial sources. The $\mathrm{C}^{14}$-labeled urea had a specific activity of $4 \mathrm{mc}$ per mmole. Tritiated water of high specific activity was diluted with physiologic saline to contain $0.5 \mathrm{mc}$ per $\mathrm{ml}$. For the experiments on primates $5.9 \mathrm{mg}$ of lyophylized radiourea was dissolved in $0.5 \mathrm{ml}$ of sterile saline and mixed with $1 \mathrm{ml}$ of the diluted tritium solution.

Synthesis of urea- $C^{13}$. Sodium cyanate- $\mathrm{C}^{13}$ was prepared from sodium cyanide- $\mathrm{C}^{13}$ by oxidation with permanganate according to the procedure of Gall and Liebermann (7). The purified sodium cyanate was then allowed to react with ammonium sulfate in aqueous solution. The urea was removed from the crude reaction mixture by continuous extraction with ethanol followed by recrystallization from ethanol and acetone. From $1.0 \mathrm{~g}$ isotopic sodium cyanide, $450 \mathrm{mg}$ of urea, $\mathrm{mp} 132^{\circ}$ to $134^{\circ}$, was obtained. Carrier dilutions were prepared from this material and subjected to the action of urease in the manner described below. Mass spectrographic analyses of the resulting carbon dioxide indicated that the original material contained 54.8 per cent $\mathrm{C}^{13}$ excess. For the physiologic experiments a 1 per cent solution of pure urea- $\mathrm{C}^{13}$ in sterile physiologic saline was employed.

Physiologic experiments. Pregnant rhesus monkeys at term were used for these experiments. An effort was made to allow the pregnancies to continue after the completion of each procedure and ultimately to obtain a normal, living baby. The general procedure was essentially that described in previous reports $(8,9)$ except for the collection of microsamples.

Catheters were placed in the maternal femoral artery, an interplacental vessel, and the amniotic cavity. Each of these was provided with a 3-way stopcock. At the beginning of each experiment control samples for the quantitative determination of urea were obtained from each of the body fluids. One or two additional samples were taken in an intermediate period during the experiment in order to be sure that the concentration of urea had not changed in the interim. 
The total amounts of radioactive material injected into mother, fetus, or amniotic fluid were adjusted so that a 100 -fold dilution of a sample would be more than that necessary to perform the counting of the final carbon dioxide carrier solution with an accuracy of at least 5 per cent. When $0.5 \mathrm{mc}$ of $\mathrm{C}^{14}$ was used, a sample of $0.02 \mathrm{ml}$ of fetal blood was adequate. In the experiments where $\mathrm{C}^{13}$ was used, $0.5 \mathrm{ml}$ of sample was necessary for the mass spectrographic analyses and determination of radioactivity.

When samples were withdrawn, 0.5 to $1.0 \mathrm{ml}$ of blood or amniotic fluid was aspirated into a tuberculin syringe, and the stopcock turned so that a small amount of blood or amniotic fluid welled up into the second empty cup. The desired sample, usually $0.02 \mathrm{ml}$, was then removed by micropipet and added to $2 \mathrm{ml}$ of a carrier solution containing a known amount of urea. For the determination of tritium a small amount of the blood or amniotic fluid remaining in the stopcock cup was aspirated into an open melting-point tube which was then sealed. The sample remaining in the syringe was then reinjected into the compartment from which it was withdrawn.

Quantitative analyses. The urea concentrations in amniotic fluid and in maternal and fetal blood were determined by the manometric urease method of Van Slyke (10). The blood volumes were estimated by injecting chromium-labeled maternal or fetal red cells and measuring their dilution. The amniotic fluid volume was estimated by the Congo red method of Neslen, Hutchinson, Hallet and Plentl (11) or by extrapolation of the tritium activity curves.

Radioactivity. For the determination of tritium in blood and amniotic fluid samples, 1 drop was sublimed into the conversion apparatus of Graff and Rittenberg (12). The remainder of the procedure was essentially that described in previous reports (9).

For the determination of $\mathrm{C}^{14}$ the carrier mixtures were treated in exactly the same manner as the quantitative procedures except for the omission of the final step, the reabsorption of carbon dioxide with sodium hydroxide. The gas mixture containing a small amount of noncondensible gases and water vapor was then transferred to previously evacuated breakseal tubes. For the determination of radioactivity the apparatus described in a previously reported study was used. Counting of the final carbon dioxide-methane mixture was performed in the proportional region, and the results were expressed as counts per minute per millimole. These were then corrected for $(a)$ nonisotopic carbon dioxide originating from the enzyme solution and $(b)$ the urea concentration in the original body fluid.

Mass spectrographic analyses. Carbon dioxide was prepared in the Van Slyke manometric apparatus as described above, collected in evacuated glass tubes, and sealed. The mass spectrographic analyses were performed in the usual manner and the results expressed as per cent $\mathrm{C}^{13}$ excess. $^{1}$

1 The authors are indebted to Dr. Rittenberg and Dr. Sucher for performing these analyses.

\section{RESULTS}

Single urea tracer. Three preliminary experiments were performed as a basis for the more complex but also more informative double tracer studies. Urea-C ${ }^{14}$ and tritiated water were injected into the maternal vascular tree in the first experiment, into the fetal circulation in the second, and into the amniotic fluid in the third. The results expressed as specific activity for $\mathrm{C}^{14}$ and tritium are reproduced graphically in Figures 1, 2 , and 3.

Double urea tracers. In the two final experiments urea-C $\mathrm{C}^{13}$ and urea-C $\mathrm{C}^{14}$ were used simultaneously; 125 and $147 \mathrm{mg}$ of urea-C $\mathrm{C}^{13}$ ( 54.8 per cent excess) dissolved in physiologic saline were injected into the maternal blood stream, and $5.9 \mathrm{mg}$ urea- $\mathrm{C}^{14}$ (4 mc per mmole) was introduced into the fetal circulation. Five-tenths $\mathrm{ml}$ samples of amniotic fluid and of fetal and maternal blood were collected over a period of 1 hour. In contrast to the preceding experiments the majority of samples were collected during the first few minutes. For the $\mathrm{C}^{14}$ analyses the samples were diluted with carrier as described above, and for the mass spectrographic analysis no carrier was employed. The results are reproduced in Figures 5 and 6 where the specific $\mathrm{C}^{14}$ activities and per cent $\mathrm{C}^{13}$ excess are plotted against time. The curves are nearly identical. For one of these experiments the fractional amounts of each tracer in the three compartments are reproduced in Figure 7 . Additional significant analytic and other data are given in Table II.

\section{DISCUSSION}

The transfer of urea, the major metabolic end product of fetal nitrogen metabolism, has received relatively little attention in the field of chemical embryology. In two of the most recent and exhaustive reviews of placental physiology the subject is not even mentioned. To date investigators reporting on the subject $(2,13,14)$ have employed methods that depend upon the demonstration of concentration gradients on either side of the placental barrier or on differences in the concentration of umbilical arterial and venous blood $(15) .^{2}$ In the former instance, a gradient must

${ }^{2}$ As shown in the body of this report the metabolic rate of urea production is probably less than $0.2 \mathrm{mmole}$ 
TABLE I

Summary of analytic data for the three experiments *

\begin{tabular}{lccc}
\hline & \multicolumn{3}{c}{ Urea concentration } \\
\cline { 2 - 4 } & $\begin{array}{c}\text { Fetal } \\
\text { blood }\end{array}$ & $\begin{array}{c}\text { Maternal } \\
\text { blood }\end{array}$ & $\begin{array}{c}\text { Amniotic } \\
\text { fluid }\end{array}$ \\
\hline Experiment I & & $m g / 100 \mathrm{ml}$ & \\
$\quad$ Control & 16.6 & 15.9 & 20.5 \\
Termination & 16.2 & 16.2 & 22.0 \\
$\quad$ (200 minutes) & & & \\
$\begin{array}{l}\text { Experiment II } \\
\text { Control }\end{array}$ & & & \\
Termination & 44.1 & 45.1 & 52.0 \\
$\quad(190$ minutes) & 41.0 & 45.0 & \\
$\begin{array}{l}\text { Experiment III } \\
\text { Control }\end{array}$ & & & \\
60 minutes & 19.1 & 20.7 & 36.3 \\
Termination & 17.6 & 20.5 & \\
$\quad(215$ minutes) & 17.3 & 20.6 & 36.0 \\
\hline
\end{tabular}

* The determinations were carried out according to standard techniques (9).

be produced artificially by raising the maternal urea concentration above physiologic levels; the latter approach is based on the premise that the placenta is inert. Actually the placenta is metabolically quite active (16), and Brandstrup (14) has shown that its permeability to urea has certain limitations. For these reasons no convincing evidence exists to demonstrate that under normal physiologic conditions a transfer or exchange of urea takes place.

In the present experiments an attempt has been made to approach the physiologic state as closely as possible. Maternal anesthesia was maintained at a minimum, and adequate oxygenation was insured by endotracheal intubation of the mother. At no time during the experiment or in the immediate postoperative period did any of the animals show signs of anoxia, and in all cases live baby monkeys were obtained 3 to 12 days after the operative procedures. The total amount of blood withdrawn from mother and fetus was 0.7 $\mathrm{ml}$, or less than 2 per cent of the estimated fetal-

per hour per kg fetus, which for the human corresponds to $(0.20)(3.3) / 60=0.011$ mmole per minute or $0.66 \mathrm{mg}$ per minute. For a placental blood flow of $360 \mathrm{ml}$ per minute this corresponds to an $\mathrm{A}-\mathrm{V}$ difference of $0.184 \mathrm{mg}$ per $100 \mathrm{ml}$, which would be difficult to define with any degree of precision. placental blood volume and a negligible percentage of the mother's blood.

The amount of urea injected in the first three experiments was $5.9 \mathrm{mg}$. This represents 1.5 per cent of the total maternal urea pool, an increment that could not have any demonstrable effect on the "steady state" of the system. When the urea was injected into the fetal circulation (Figure 2), however, the total amount of urea in the fetal blood compartment was obviously increased, and a steady state was not achieved. The same initial disturbance occurred during the beginning of the third experiment (Figure 3 ) in which the tracers were injected into the amniotic fluid. Despite these theoretic objections, the actual variations in the urea concentrations were minimal (Table I).

Tritium injected into the same compartment as labeled urea represents a particularly sensitive monitoring device which would make it possible to detect any inconsistency or contamination of the samples. The specific-activity curves for

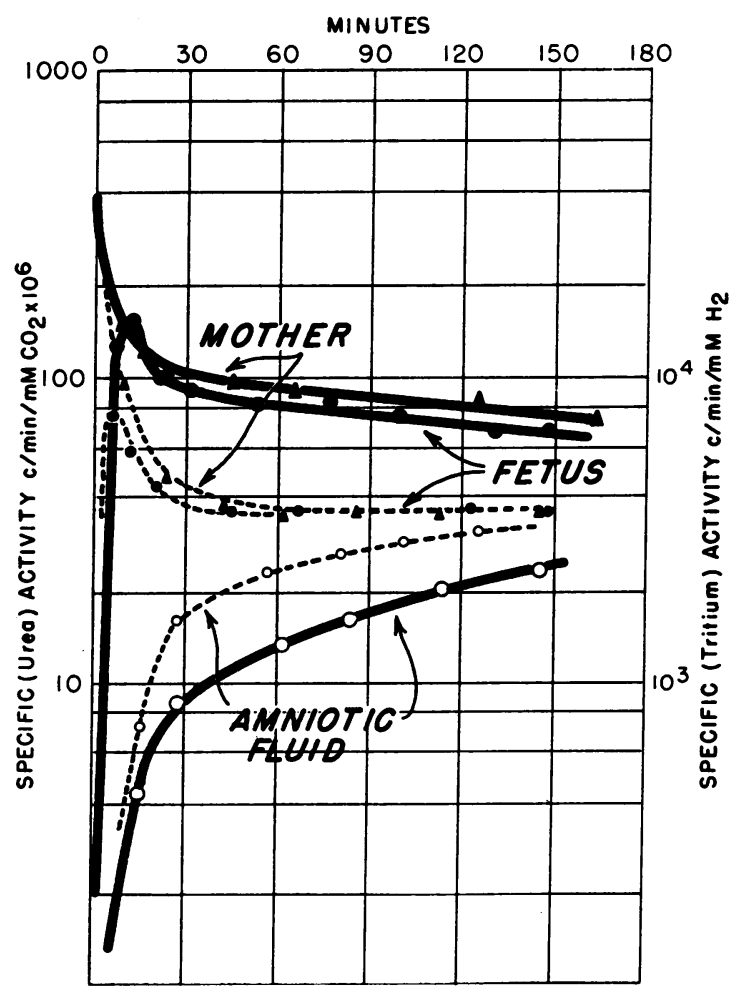

Fig. 1. Specific uRea (SOlid line) and tRitium aCTIVITY (DOTTED LINE) FOR AMNIOTIC FLUID AND MATERNAL AND FETAL BLOOD AS A FUnCtion OF time. Urea-C ${ }^{14}$ and tritiated water were injected into the maternal circulation. 
tritium are shown by dotted lines in Figures 1, 2, and 3. They are identical with those obtained in previous experiments (9), and it can be concluded that no gross error or contamination occurred in the collection of urea samples.

The analytic method based upon the enzymatic liberation of carbon dioxide from blood and amniotic fluid samples is highly specific, but the values must be carefully corrected for inevitable variations in the enzyme control. That radiourea does not interfere with the determination of radioactive volatile carbon dioxide has been shown previously (8). Conversely, large quantities of radioactive acid-volatile carbon dioxide could conceivably influence the values obtained for urea. The error contributed in this manner, nevertheless, could not have been very large, for there was no detectable activity in the acid-volatile fractions of fetal and of maternal blood.

Interpretation of tracer curves. The three preliminary experiments in each of which the tracer was injected into a different compartment yielded nine specific-activity curves. The conditions under which these three experiments were carried out were nearly identical, and with some reser-

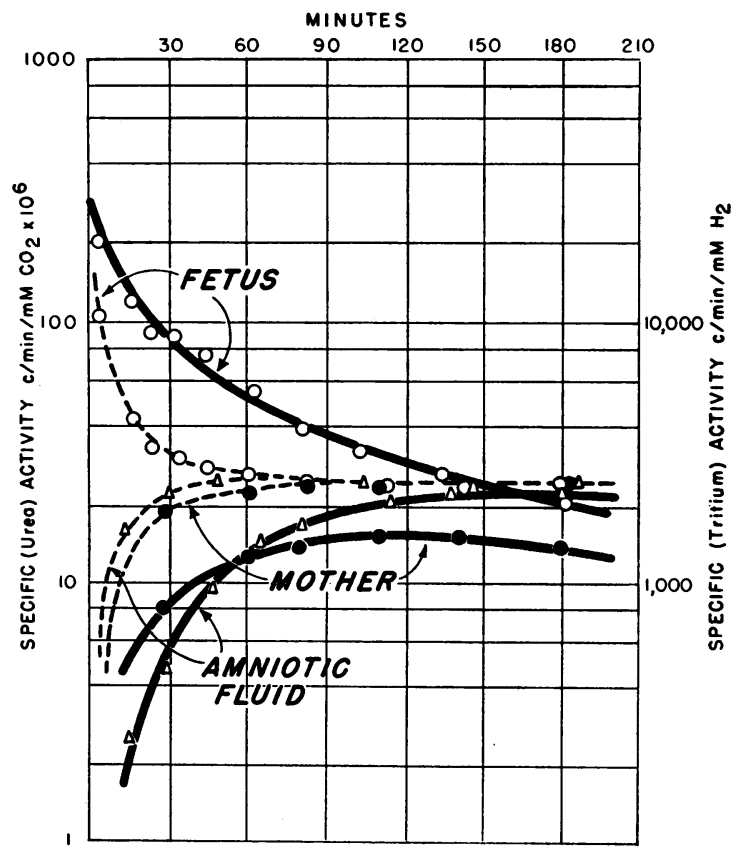

Fig. 2. Specific uRea (SOlid line) ANd tritium aCTIVITY (DOTTED LINE) FOR AMNIOTIC FLUID AND MATERNAL AND FETAL BLOOD AS FUNCTION OF TIME. The tracer mixture was injected into the fetal circulation.

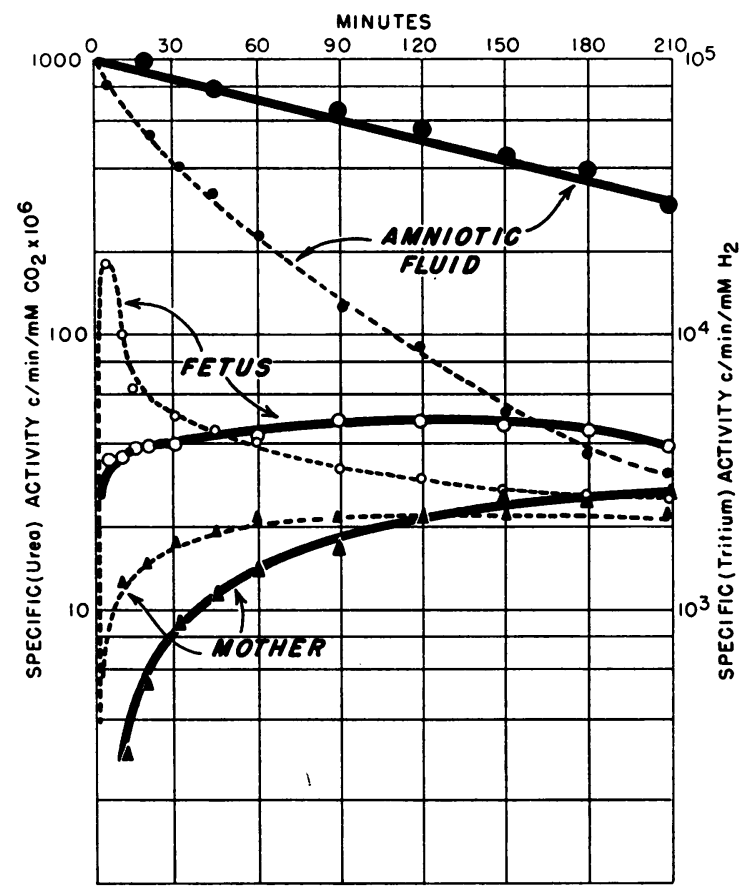

Fig. 3. Specific uRea (SOlid line) and tritium aCTIVITY (DOTTED LINE) FOR AMNIOTIC FLUID AND MATERNAL AND FETAL BLOOD AS A FUNCTION OF TIME. The tracer mixture was injected into the amniotic fluid.

vations the three sets of curves can be considered as representing the system.

The simplest possible model representing this system would contain five compartments and a minimum of 11 significant or possible transfer rates (Figure 4). The experimental data are not accurate enough for an analysis of such a complicated system, but a qualitative interpretation of the curves might give some information on the relative magnitude of these exchanges.

When radiourea was injected into the maternal circulation, the specific-activity curves of Figure 1 were obtained. The curve for maternal blood is very similar to that obtained on the adult human

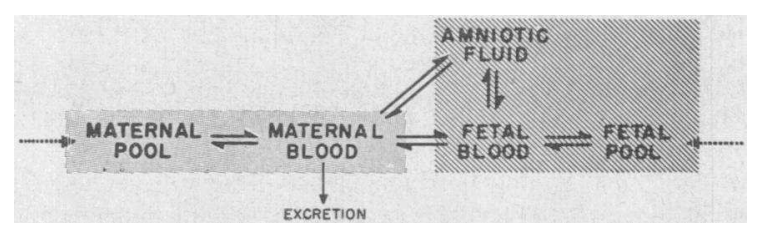

Fig. 4. A HYPOTHETIC MODEL OF THE UREA FLUXES IN THE PREGNANT ORGANISM. Solid arrows indicate assumed transfer rates; dotted arrows designate the rate of endogenous urea production. 
by Rittenberg (17), who used $\mathrm{N}^{15}$ for this purpose. The initial rapid decline is believed to be due to a distribution into the general urea pool. The subsequent slower disappearance reflects the metabolic rate, i.e., a dilution by endogenous urea. This endogenous dilution corresponds to a disappearance constant of 0.00268 per minute or a halftime of 4.3 hours. For the adult human the halftime of $\mathrm{N}^{15}$ labeled urea was 8 hours (17). In view of the higher metabolic rates of primates (18), a faster turnover should be expected. As shown below the urea pool is about $84 \mathrm{mg}$ per $\mathrm{kg}$; hence the rate of urea metabolism for the adult primate is $(0.00268)(84)=0.22$ mmole per hour per $\mathrm{kg}$.

Simultaneously with the decline of the tracer in maternal blood, the specific activity curve for the fetus rises sharply, crosses the maternal curve twice, and then declines at a rate nearly identical with the maternal. This double crossing of the maternal curve is probably due to a temporary accumulation of the tracer in fetal blood, i.e., a sampling error rather than a characteristic of the system. In any case, the rapid equilibration of the tracer points to a direct transfer of urea from mother to fetus.

Radiourea also appears in the amniotic fluid which may come directly from the mother $(a)$ or be the result of transmission by the fetus $(b)$.

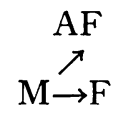

(a)

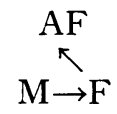

(b)
The urea compartments in fetus and $\mathrm{AF}$ are nearly equal, yet the tracer curves of Figure 1 for these compartments are widely different. If a direct transfer from $\mathrm{M}$ to $\mathrm{AF}$ exists $(a)$, then this transfer must be appreciably slower than is the transfer from $M$ to $F$.

In the second experiment the tracer was injected into fetal blood and appeared in both secondary compartments ( $\mathrm{AF}$ and $\mathrm{M}$ ). The maternal specific urea activity rises rapidly to reach a maximum in about 120 minutes. The amniotic fluid curve exhibits a similar pattern, reaching a maximum slightly later. This transfer from fetus to secondary compartments may occur simultaneously $(c)$ or via the medium of maternal blood only $(d)$. Since the maternal urea (blood) com- partment is about 10 times larger than the urea contained in the AF, the similarity of the activity curves ( $A F$ and $M$ ) suggests that the transfer from $\mathrm{F}$ to $\mathrm{M}$ must have been appreciably larger than the transfer from $\mathrm{F}$ to $\mathrm{AF}$. A transfer from fetus to mother exclusively via the amniotic fluid (e) is not possible because the maternal curve passes through a maximum before, not after, the AF urea activity.
$\mathrm{AF}$
$\mathrm{M} \leftarrow \mathrm{F}$

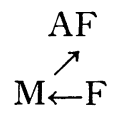
$\stackrel{\mathrm{AF}}{\swarrow \nwarrow}$
$\stackrel{\mathrm{AF}}{\swarrow \swarrow} \mathrm{K}$
(c)
(d)
(e)
$(f)$

Figure 2 could, therefore, be explained on the basis of scheme $(d)$ only, and a direct transfer from $\mathrm{F}$ to AF, $(c),(e)$, and $(f)$, is not established.

Figure 3 , where the AF served as a primary compartment, constitutes evidence for a transfer from AF to $F$. The previously established transfer from fetus to mother then accounts for the rapid rise in maternal specific urea activity which predictably reaches its maximum much later than the fetal curve. If a direct transfer from $\mathrm{AF}$ to $\mathrm{M}$ occurs at all, it must be very small compared with the transfer from AF to $\mathrm{F}$. The only additional information derived from the third experiment is a transfer from AF to $\mathrm{F}$.

In summary the data obtained in the preliminary experiments establish most but not all transfer rates of the hypothetical model. They cannot be used to decide whether the urea of the amniotic fluid is derived from fetus, or mother, or both, and whether there exists a direct transfer from amniotic fluid to mother bypassing the fetus. Additional information on the existence of these pathways can be obtained from the subsequent experiments in which two tracers for urea were used simultaneously.

The use of two tracers has several advantages in addition to the fact that they clearly illustrate the opposing fluxes. When only a single tracer and different animals are used, each specific-activity curve is based on individual analyses (compartmental size) and is thus subject to a considerable error. The relative magnitude of each transfer rate may vary considerably from one animal to another, and it would, therefore, be difficult to compare opposing fluxes. When these opposing fluxes are studied in the same animals and two 
different tracers are used, most of these errors are eliminated, for any inaccuracy in the basic analytic values would apply to both sets of curves. The curves are so interrelated that the experimental error in the determination of the basic values, e.g., compartmental size and carrier dilution, has no significant effect on their relative position. Despite this inherent cancellation of errors, the data are not suited for a complete analysis of a 5-compartment system because it has not been possible to approach a steady state, at least not to the same extent as in the first three experiments. Although the $\mathrm{C}^{14}$-labeled urea had a sufficiently high specific activity leading to a moderate increase of the total fetal blood urea, the amount of $\mathrm{C}^{13}$-labeled urea injected into the maternal pool doubled the maternal blood urea compartment.

These double tracer experiments are essentially analogous to the preceding experiments shown in Figures 1 and 2 but were performed simultaneously on the same animal. Both fetus and mother

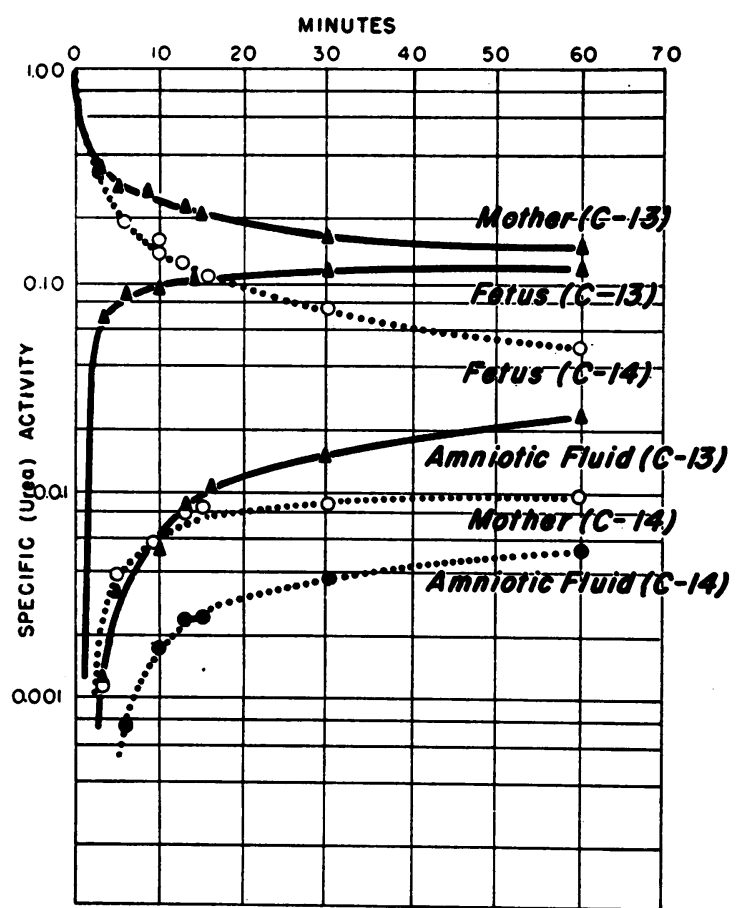

Fig. 5. Specific URea-C ${ }^{14}$ activity (dotted curves) AND PER CENT $C^{13}$ EXCESS (SOLID CURVES) IN AMNIOTIC FLUID, AND FETAL AND MATERNAL BLOOD AS A FUNCTION of TIME. Urea- $\mathrm{C}^{13}$ was injected into the maternal and urea-C $\mathrm{C}^{14}$ into the fetal circulation. For purposes of comparison the calculated initial values for the two tracers in the primary compartments are equal to unity.

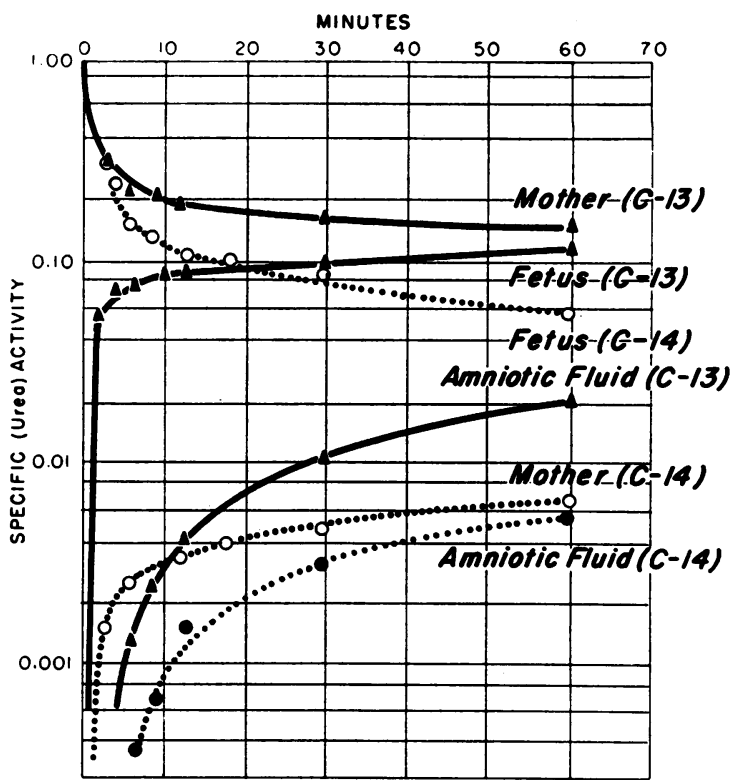

Fig. 6. Specific activity CuRves and PeR CENT $C^{13}$ EXCESS AS A FUNCTION OF TIME. The data were obtained under conditions identical with those of the preceding experiment.

served as primary compartments (Figures 5 and 6 ), and their specific-activity curves can now be compared. In the absence of a placental exchange these two primary curves would be expected to be identical since the distribution in their respective pools should be the same. The rapid exchange of urea between maternal and fetal blood leads to a relatively faster dilution of the tracer in fetal blood as shown in Figures 5 and 6 . The evident difference in the two curves does not imply a difference in urea metabolism of adult and fetal organism.

The size of the maternal pool can be estimated from the flat portion of the specific activity curve (Figure 5). If this is assumed to be straight and is extrapolated to $t=0$, it intersects the ordinate at 0.22 , corresponding to a dilution of 22 per cent. Since $82.2 \mathrm{mg}$ of urea- $\mathrm{C}^{13}$ was injected, the maternal urea pool is $82.2 / 0.22=374 \mathrm{mg}$, and for a maternal weight of $4.5 \mathrm{~kg}$ this corresponds to $83.1 \mathrm{mg}$ per $\mathrm{kg}$, a value that is almost identical with that reported for the human (17). If the present observations had been extended for a longer period (4 hours or more), this datum could be checked by an analogous extrapolation of the fetal urea-C ${ }^{14}$ curve.

The single tracer experiments reproduced in 


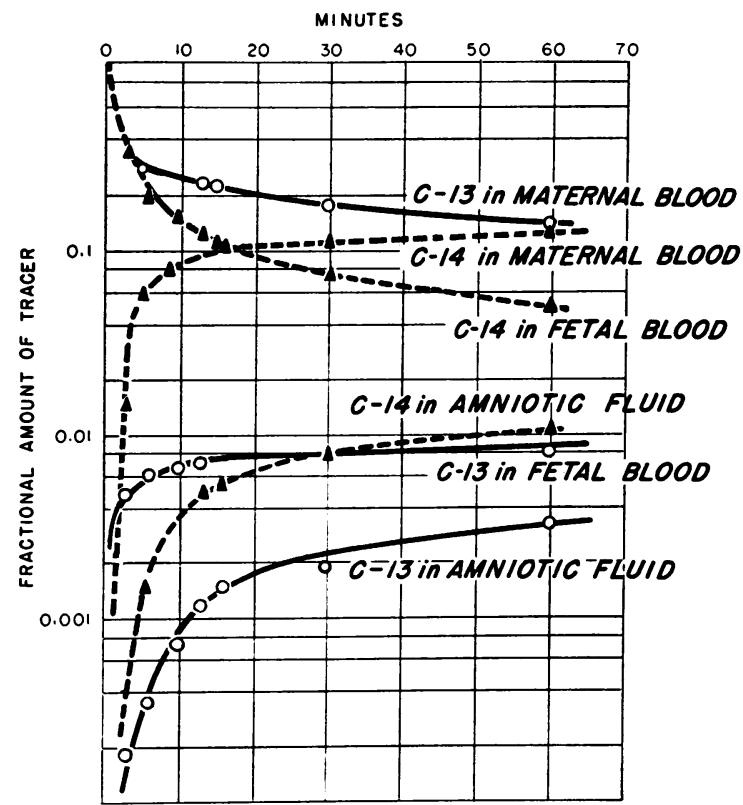

Fig. 7. The FRACtional amounts OF EACH TRACER IN THE THREE COMPARTMENTS CALCULATED FROM THE data of Figure 5, the control values of Table II, AND THE AMOUNT OF LABELED UREA ADDED TO EACH OF THE PRIMARY COMPARTMENTS.

Figures 1 and 2 did not permit a definite conclusion concerning the transfer to the amniotic fluid. The specific-activity curves in Figures 5 and 6 where both tracers were used simultaneously can supply a partial answer to this question. The curves reproduced in Figures 5 and 6 demonstrate that the percentage of $\mathrm{C}^{13}$ in the amniotic fluid is consistently and appreciably higher than its $\mathrm{C}^{14}$ specific activity. This is consistent with but does not prove the existence of a direct transfer from mother to amniotic fluid.

If the fractional amounts rather than specific activities are examined, some additional information regarding the transfers to the amniotic fluid can be obtained. These fractional amounts, reproduced in Figure 7 as a function of time, were calculated from the specific-activity values of Figure 5 and the estimated total amount of urea in each compartment at the beginning of the experiment. For both primary compartments (maternal and fetal blood) the amount of labeled material introduced must be added to that originally present. For the fourth experiment (Table II) the ratio of the initial urea content of amniotic fluid and of maternal and fetal blood was $2.02: 14: 1$ when the fetus served as primary compartment and $0.144: 1: 0.0714$ when the tracer was injected into the maternal blood stream. That fetus and mother contribute to the urea of the amniotic fluid is shown by the ratio of the two tracers. At 60 minutes the $C^{14}$ fraction amounts to (1.1) (100)/ $12=9.1$ per cent, whereas the $C^{13}$ fraction is only $(0.35)(100) / 14=2.5$ per cent of the maternal value. Part or all of the former tracer (urea- $\mathrm{C}^{14}$ ) must have been contributed from sources other than the maternal compartment, i.e., the fetus.

The actual quantities transferred per unit of time cannot be estimated with any degree of accuracy. Only a minimal value can be derived from the tracer content in the earliest samples of amniotic fluid when the contribution from secondary compartments is small or negligible. At 6 minutes the amniotic fluid contained 0.035 per cent of the urea- $\mathrm{C}^{13}$ injected into the mother and 0.15 per cent of the urea- $\mathrm{C}^{14}$ injected into the fetus (Figure 7). For a blood urea pool of $16 \mathrm{mg}$ for the fetus and $228 \mathrm{mg}$ for the mother, the minimal quantities transferred would be $(16)(0.15) /(100)$ $(6)=0.004 \mathrm{mg}$ urea-C $\mathrm{C}^{14}$ and $(228)(0.035) /$ $(100)(6)=0.013 \mathrm{mg}$ urea- $\mathrm{C}^{13}$ per minute. The ratio of these transfer rates indicates that the amniotic fluid receives about three times as much urea from the mother as it does from the fetus. The established pathways now include schemes $(a)$ and $(b)$.

TABLE II

Significant and supportive data on the two experiments in which urea- $C^{13}$ and urea-C $C^{14}$ were employed simultaneously*

\begin{tabular}{|c|c|c|}
\hline & $\underset{\text { IV }}{\text { Experiment }}$ & $\underset{V}{\text { Experiment }}$ \\
\hline Weight of mother, $\mathrm{kg}$ & 4.56 & 6.55 \\
\hline Weight of fetus, $\mathrm{kg}$ & 0.435 & 0.380 \\
\hline Weight of placentae, $\mathrm{kg}$ & 0.085 & 0.101 \\
\hline Volume of maternal blood, $m l$ & 300 & 420 \\
\hline Volume of fetal blood, $m l$ & 43 & 38 \\
\hline Volume of amniotic fluid, $m l$ & 100 & 80 \\
\hline $\begin{array}{l}\text { Conc. of urea in maternal } \\
\text { blood, } m \mathrm{~g} / 100 \mathrm{ml}\end{array}$ & 27.0 & 21.4 \\
\hline $\begin{array}{l}\text { Conc. of urea in fetal } \\
\text { blood, } m \mathrm{mg} / 100 \mathrm{ml}\end{array}$ & 24.1 & 26.3 \\
\hline $\begin{array}{l}\text { Conc. of urea in amniotic } \\
\text { fluid, } m \mathrm{~m} / 100 \mathrm{ml}\end{array}$ & 33.0 & 30.9 \\
\hline $\begin{array}{l}\text { Amount of urea- } \mathrm{C}^{13} \text { added } \\
\text { to maternal blood, } \mathrm{mg}\end{array}$ & 147 & 125 \\
\hline $\begin{array}{l}\text { Amount of urea-C } \mathrm{C}^{14} \text { added } \\
\text { to fetal blood, } \mathrm{mg}\end{array}$ & 5.9 & 5.9 \\
\hline
\end{tabular}

* The concentration of urea in amniotic fluid and in maternal and fetal blood was estimated before the addition of the tracer. 
Evidence has been presented for the existence of all transfers shown in Figure 4 except the flux from amniotic fluid to maternal blood. This problem could be investigated by designing experiments analogous to the present double tracer studies in which the amniotic fluid rather than the mother would serve as one of the primary compartments. The necessity of using large amounts of $\mathrm{C}^{13}$ would preclude this approach.

If the fetus produces urea, then its endogenous urea production must result in a net transfer from the products of gestation to the maternal organism as represented by a difference in transfer rates from and to the maternal organism. For a calculation of these rate constants it is necessary to simplify the proposed 5-compartment system by assuming a unidirectional transfer from the primary compartment to each of the accessible secondary compartments. For example, when the tracer is injected into the maternal circulation, the backflow from fetal blood to mother and to extravascular fetal compartments is negligible at the beginning of the experiment. For the first few minutes the transfer to fetal blood, $d F / d t$, will be proportional to $M$, the tracer content of maternal blood.

$$
\frac{d F}{d t}=\lambda M
$$

As long as all flows from fetal blood compartment are negligible, Equation 1 is valid, but for increasing values of $t$ neither the slope of the fetal curve nor the amount of tracer in maternal blood is constant. When the symbol $\rho$ instead of $\lambda$ is used for points other than $t=0$, the equation becomes

$$
\rho=\frac{[d F / d t]_{t}}{[M]_{t}}
$$

with the numerator representing the slope of the fetal (secondary) curve and the denominator representing the corresponding, simultaneously determined amount of tracer in the maternal (primary) compartment. The value of $\rho$ thus changes with time and, if extrapolated to $t=0$, approaches the value of $\lambda$.

The fractional amounts of each tracer in each compartment can be determined from the specificactivity curves and a knowledge of the compartmental size. In Figure 7 these fractional amounts calculated from the data of Figure 5 are plotted against time. The slopes for each secondary compartment can thus be determined for each experimental point by using a Cartesian coordinate system. These values divided by the fractional tracer content in the primary compartment give the value of $\rho$ for each value of $t$ as shown in Figure 8. The function $\rho$ increases rapidly with decreasing values of $t$ and the extrapolated value of $\lambda$ is thus subject to an appreciable error: $0.0035 \pm 0.0005$ per minute for the transfer rate from mother to fetus and $0.06 \pm 0.01$ in the opposite direction. Multiplication of the $\lambda$ 's by the total amount of urea in each primary compartment according to Equation 1 gives the total amount of urea transferred. The blood urea pool for the $435-\mathrm{g}$ fetus

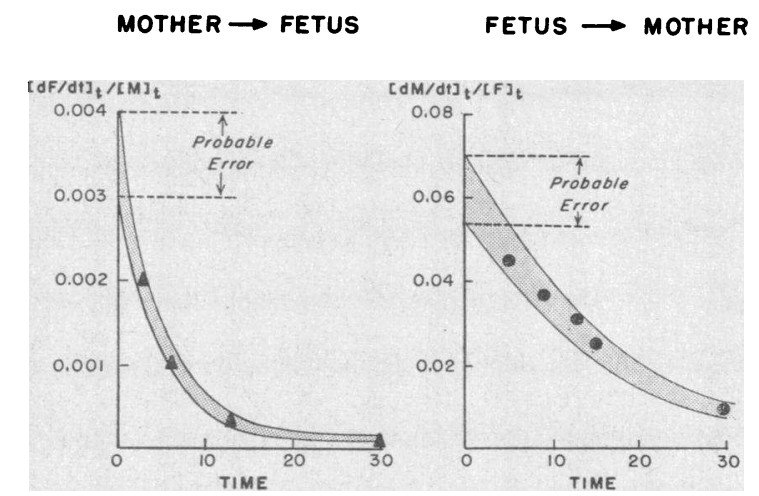

Fig. 8. The FUnCtions $[d F / d t]_{t} /[M]_{t}$ AND $[d M]_{t} /$ $[d F]_{t}$ PLOTTED AGAINST TIME FOR EXTRAPOLATION to $t=0$. The shaded area represents the estimated error.

was $16.3 \mathrm{mg}$, hence the amount transferred from fetus to mother was $(16.3)(0.06) / 0.435=2.25$ $\mathrm{mg}$ per minute per $\mathrm{kg}$; for a maternal blood pool of $228 \mathrm{mg}$ the transfer rate from mother to fetus was $(228)(0.0035) / 0.435=1.83 \mathrm{mg}$ per minute per $\mathrm{kg}$ fetus. For the second double tracer experiment these opposing transfer rates were calculated in similar manner and found to be 1.36 and $1.13 \mathrm{mg}$ per minute per $\mathrm{kg}$ respectively.

With the maximal error for these opposing transfer rates taken into account, it is unfortunately not possible to define a net value for the transfer from fetus to mother. If the endogenous urea production of the fetus is proportional to that of the adult $(0.2$ mmole per hour per $\mathrm{kg})$, this net transfer amounts to only a fraction of the total placental exchange. 


\section{SUM MARY}

Urea- $\mathrm{C}^{13}$ has been synthesized from sodium cyanide- $\mathrm{C}^{13}$. Its analysis in body fluids is described. Methods were developed and tested for the determination of specific urea $\left(\mathrm{C}^{14}\right)$ activity in blood and amniotic fluid using not more than $0.02 \mathrm{ml}$ of these body fluids. This was accomplished by using radiourea of high specific activity and isolation of urea carbon by carrier dilution methods.

Pregnant rhesus monkeys at term were subjected to routine operative procedures for the placement of catheters into maternal arteries, interplacental vessels, and amniotic fluid. A mixture of urea-C $\mathrm{C}^{14}$ and tritium oxide was injected into one of these compartments and multiple samples collected over a period of several hours. These were analyzed for urea- $\mathrm{C}^{\mathbf{1 4}}$ and tritium activity.

In two additional experiments urea- $\mathrm{C}^{13}$ and urea- $\mathrm{C}^{14}$ were injected simultaneously into the fetal and maternal blood stream. Samples of amniotic fluid and of fetal and maternal blood were then analyzed for their urea- $\mathrm{C}^{13}$ and urea- $\mathrm{C}^{14}$ content for study of the opposing fluxes.

The specific-activity curves from the first set of experiments indicated that radiourea is distributed in a general urea pool the size of which could be estimated as $84 \mathrm{mg}$ per $\mathrm{kg}$ for the mother. There is a rapid exchange of urea between the maternal and fetal blood and an appreciably slower transfer to the amniotic fluid. The specific-activity curves for the simultaneously injected tracers indicated that the urea of the amniotic fluid is derived from mother and fetus in an approximate ratio of $3: 1$. The exchange rate between maternal and fetal blood could be estimated as 1 to 2 mmoles of urea per hour per kilogram fetus.

The large inherent error in estimation of these opposing fluxes made it impossible to demonstrate a net transfer of urea from fetus to mother. The maximal rate of endogenous urea production in the fetal organism amounts to less than one-tenth of the total placental exchange.

\section{REFERENCES}

1. Needham, J. Chemical Embryology. Cambridge Univ. Press, 1931, vol. 3, p. 1531.

2. Anselmino, K. J. Über die Permeabilität der Placenta. I. Mitteilung. Die Grenzen der "Physi- kalischen Permeabilität" für Anelektrolyte an der Kaninchenplacenta. Arch. Gynäk. 1929, 138, 710 725.

3. Luck, J. M., and Engle, E. T. The permeability of the placenta of the rat to glycine, alanine and urea. Amer. J. Physiol. 1929, 88, 230.

4. Fromherz, C., and Gugert, H. Chemische Untersuchungen versichiedener Theile des menschlichen Koerpers, u.s.w. in Jahrbuch der Chemie und Physik, Halle, von Schweiger, 1827, vol. 20.

5. Davies, J. Physiology of fetal fluids in Transactions of the Fourth Conference on Gestation, C. A. Villee, Ed. New York, Josiah Macy, Jr. Foundation, 1957, p. 11.

6. Prochownick, L. Beiträge zur Lehre vom Fruchtwasser und seiner Entstehung. Arch. Gynäk. 1877, 11, 304.

7. Gall, H., and Liebermann, G. Über Oxidation von Alkalicyanide durch Alkalipermanganat. Ber. dtsch. chem. Ges. 1928, 61, 675.

8. Friedman, E. A., Gray, M. J., Grynfogel, M., Hutchinson, D. L., Kelly, W. T., and Plent1, A. A. The distribution and metabolism of $C^{14}$-labeled lactic acid and bicarbonate in pregnant primates. $\mathrm{J}$. clin. Invest. 1960, 39, 227.

9. Friedman, E. A., Gray, M. J., Hutchinson, D. L., and Plentl, A. A. The role of the monkey fetus in the exchange of the water and sodium of the amniotic fluid. J. clin. Invest. 1959, 38, 961.

10. Van Slyke, D. D. Determination of urea by gasometric measurements of the carbon dioxide formed by the action of urease. J. biol. Chem. 1927, 73, 695.

11. Neslen, E. D., Hutchinson, D. L., Hallet, R. L., and Plentl, A. A. Dilution methods for determination of amniotic fluid volume. Obstet. and Gynec. 1954, 3, 598.

12. Graff, J., and Rittenberg, D. Microdetermination of deuterium in organic compounds. Analyt. Chem. 1952, 24, 878.

13. Brandstrup, E. Über den Stoffaustausch zwischen Mutter und Fetus. Klin. Wschr. 1928, 7, 2340.

14. Brandstrup, E. Über die Diffusion der Glucose und des Harnstoffes durch die Placenta. Acta obstet. gynec. scand. 1929, 8, 490.

15. Setnikar, I., and Barron, D. H. The maternal-fetal nitrogen exchange in the goat. Quart. J. exp. Physiol. 1958, 43, 284.

16. Botella-Llusia, J. Die Harnstoffbildung der menschlichen Placenta. Arch. Gynäk. 1935, 159, 27.

17. Rittenberg, D. A method for the evaluation of the rate of protein synthesis in man in Ciba Foundation Conference on Isotopes in Biochemistry, G. E. W. Wolstenholme, Ed. Philadelphia, Blakiston, 1951, p. 190.

18. Spector, W. S. Handbook of Biological Data. Philadelphia, Saunders, 1956, p. 258. 